\title{
The Role of Pomelo Peel Extract for Experimentally Induced Wound in Diabetic Rats
}

\author{
Asser Ashraf Ahmad', Ihab Ibrahim Al Khalifa², Zead Helmi Abudayeh ${ }^{3 *}$
}

\section{Asser Ashraf Ahmad', Ihab Ibrahim Al Khalifa², Zead Helmi Abudayeh ${ }^{3 *}$}

\section{'Department of Pharmacy Science / pharmacology /Applied Pharmaceuti- cal Science and Clinical Pharmacy/ Faculty of Pharmacy, Al-Isra University, Amman, JORDAN. \\ ${ }^{2}$ Department of Pharmacology and Toxicology/Pharmacy/AL-Rasheed University, Baghdad, IRAQ. \\ ${ }^{3}$ Pharmaceutical Chemistry and Phar- macognosy/Applied Pharmaceutical Science and Clinical Pharmacy Depart- ment / Faculty of Pharmacy, Al-Isra University, Amman, JORDAN. \\ Correspondence \\ Dr. Zead Helmi Abudayeh}

Department of Pharmaceutical chemistry and Pharmacognosy/ Applied Pharmaceutical Science and Clinical Pharmacy /Faculty of Pharmacy, Al-Isra University, Amman, JORDAN.

Phone no : +962797318037

E-mail: zead.helmi@outlook.com

\section{History}

- Submission Date: 16-03-2018.

- Review completed: 27-04-2018;

- Accepted Date: 27-06-2018

\section{DOI : 10.5530/pj.2018.5.149}

\section{Article Available online} http://www.phcogj.com/v10/i5

\section{Copyright}

(c) 2018 Phcog.Net. This is an openaccess article distributed under the terms of the Creative Commons Attribution 4.0 International license.

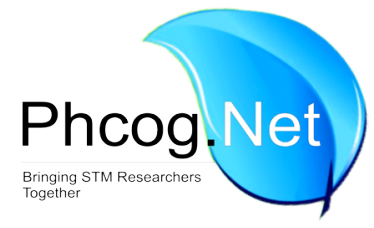

\begin{abstract}
Introduction: Delayed wound healing is a chronic complication in diabetic patients than in healthy individuals. Pomelo belongs to the genus Citrus of the family Rutaceae, an important fruit with great benefits for humans in the world. Previous studies showed that pomelo peels contain an abundant bioactive compound, which may promote wound healing in experimental animals. Aim: The current study was carried to prepare optimized extraction of pomelo peels using different experimental conditions and investigate the possible healing effect of oral treatment with pomelo peel extract (PPE) on induced excision skin wound in diabetic rats. Materials and Methods: This study was done on rats divided into five groups each of 8 rats (two treatment groups given PPE (400 and 600) $\mathrm{mg} / \mathrm{kg}$ by oral gavage compared to two control groups and standard plant for wound healing). Diabetes was induced by intraperitoneal injection of a single dose of Streptozotocin (STZ) $65 \mathrm{mgk} k$ body weight. After diabetes induction, full thickness excision wound was made in rats, and the study continued for 3 weeks. Results: This study showed significant reduction in blood glucose and both percentage and time to wound closure in the treated groups, also a significant increase in hydroxyproline and total protein content of the healed wound tissue in the treated groups compared with control groups and comparable to standard plant extract treated groups. Conclusion: Experimental data proposed that oral administration of pomelo peel extract rich in vitamins and flavonoids has a good therapeutic potential in the treatment of complicated wounds in diabetes.
\end{abstract}

Key words: Flavonoids, Pomelo, Peel, Vitamin C, Wound.

\section{INTRODUCTION}

Wound healing is a dynamic process involving many factors and cell types including soluble mediators, blood cells, fibroblasts, endothelial cells and extracellular matrix. It has been divided into several sequential phases that overlap in space and time: homeostasis, inflammation, granulation tissue formation, and tissue remodeling. ${ }^{1}$ Acute and chronic wounds affect millions of people around the world. In recent decades, clinicians have gained a better understanding of the mechanisms of normal wound repair process and causes of delays in healing. ${ }^{2}$ However, some cutaneous wounds involves complex inflammatory processes, which can lead to a more aggressive state and take longer time resulting in chronic state of inflammation. ${ }^{3}$ Diabetic wounds are complex wounds appear as cutaneous complications arise from uncontrolled diabetes mellitus caused by hyperglycemia, oxidative stress and /or microbial infections. ${ }^{4-5}$

Practices and compounds that arise from traditional medicine have been used to create the optimal conditions for the skin regeneration process and to prevent the failure of the healing process, according to the origin, these therapies are classified into herbal and animal-derived compounds. Some plants with proven wound healing action such as Aloe vera, Calendula officinalis, Portulaca oleracea and Citrus sinensis. ${ }^{6}$

Pomelo (Citrus maxima) is considered the largest citrus fruit belongs to the genus Citrus (family-Rutaceae). The fruit originated from South East Asia, commonly named shaddock in the western world. ${ }^{7}$

Previous studies have shown that pomelo fruits are a rich source of vitamin $\mathrm{C}$, flavonoids, and carotenoids, particularly in the peels. ${ }^{8}$ The major flavonoids of citrus maxima are hesperidin and naringin, and another class of O-methylated aglycones of flavones such as nobiletin and tangeretin in which strongly associated with therapeutic properties including anti-oxidant, anti-atherogenic, anti-inflammatory, anti-microbial, anti-cancer effects. ${ }^{9-12}$

Moreover, these flavonoids have been found to enhance insulin sensitivity and reduce plasma glucose levels in diabetic animal models. ${ }^{13}$

Vitamin C is necessary for the synthesis of collagen (one of the major components of connective tissue), carnitine, and enhancing the immunity of the body 
as well, vitamin C plays an important role in the wound healing process, facilitating the hydroxylation of proline and lysine for procollagen formation, ${ }^{14}$ moreover the anti-oxidant effect of vitamin $\mathrm{C}$ makes it of interest in diabetes. ${ }^{15}$ So vitamin $\mathrm{C}$ deficiency will markedly delay the wound healing by impairing the collagen formation and will also impair the previously healed wound. ${ }^{16} \mathrm{~A}$ recent study of citrus peel also exhibit a remarkable spectrum of biological activities, particularly inhibiting tumor genesis, due to the fact that peel contains high content of flavonoids. ${ }^{17}$ Moreover, analysis on Citrus maxima peel powder showed high amounts of various phenolic compounds which include phenolic acid (caffeic acid and epicatechin) and flavonoids have antioxidant properties may prevent oxidative stress, fibrosis, and hepatic damage. ${ }^{18}$

Moreover the fruit juice and peel of Citrus maxima possess both hypoglycemic and hypolipidemic properties. ${ }^{18-19}$

It has also been reported the most used parts of pomelo in traditional medicine are: leaves (epilepsy, convulsion), flowers as sedative, fruits for (Asthma and Cough), rind can be used in vomiting and diarrhea, while root and bark show good antimicrobial activity. ${ }^{20-21}$ Pomelo peel action had not been studied properly, therefore, the purpose of this study was to investigate to the possible healing effect of oral treatment with pomelo peel extract (PPE) on induced excision skin wound in diabetic rats.

\section{MATERIALS AND METHODS}

\section{Chemicals and reagents}

Streptozotocin (STZ) was purchased from Fluka (Germany), [5,5-dithiobis-(2-nitrobenzoic acid)]; 2,4-Dinitrophenyl hydrazine, thiourea, Bovin Serum Albumin (BSA), L-Hydroxyproline, Chloramine T, 4-(dimethlamino) Benz aldehyde were purchased from Sigma (Germany). All other chemicals and reagents used in this study were of analytical grade.

\section{Collection of samples}

The fruits of pomelo, Citrus maxima were collected from the local market of Amman - Jordan during the period of January-April 2016. After washing 2-3 times with running tap water the skin of the fruit was scored into quarters with sharp knife and then peeled off by fingers. The removed peels of pomelo were shade dried for about one month. All the peel samples were grinded into powder $(<90 \mu \mathrm{m})$ and the powders of the samples were kept in air-tight bottles after sieving.

\section{Preparation of Plant Extract}

According to the method reported by (Abeysinghe et al. 2007) with slight modifications, an aqueous ethanolic extract prepared by soaking $10 \mathrm{~g}$ of the dry powdered Citrus maxima peel in $100 \mathrm{ml}$ of $80 \%$ ethanol. The mixture was poured into test tubes, covered with the aluminium foils, placed into water bath for extraction at $65^{\circ} \mathrm{C}$ for $3 \mathrm{~h}$ and the whole solution was filtered, and the filtrate was transferred into a crucible where the filtrate was allowed to evaporate into dryness in an oven at $60^{\circ} \mathrm{C}$. The process was repeated several times and the yield was noted. The extract was refrigerated at $4 \mathrm{C}^{\circ}$ for future use in experimental studies. Also the required extract frequently prepared every $48 \mathrm{~h}$ and used fresh for each experiment. ${ }^{22}$ Obtained extract is a powder with light yellowish -white colour and specific pomelo odor. Preliminary phytochemical analysis revealed the presence of alkaloids, flavonoids, ascorbic acid, carotenoid, volatile oils and saponins.$^{23}$

\section{Experimental animals}

Forty male Wister albino rats weighing between 180-250 g were used in this study. Rats were obtained from animal house, Faculty of Pharmacy, Al-Isra University, Amman, Jordan. The protocol of the study was approved by Ethical Committee of the Faculty of Pharmacy, Al-Isra University. Rats were housed under standard laboratory conditions at room temperature of $23 \pm 2^{\circ} \mathrm{C}$, humidity (55\%) and were exposed to $12 \mathrm{~h}$ light/dark cycle. Animals had free access to pellet food and water ad libitum and kept one week for acclimatization before the initiation of the experiment. Animals were divided randomly into five groups each consist of 8 rats assigned as normal control (group1), diabetic control (group2), diabetic rats treated orally with $400 \mathrm{mg} / \mathrm{kg}$ PPE (group3), diabetic rats treated orally with $600 \mathrm{mg} / \mathrm{kg}$ PPE (group4) and diabetic rats treated orally with $300 \mathrm{mg} / \mathrm{kg}$ Portulaca oleracae extract (POE) as standard plant for wound healing. POE as standard plant for wound healing. ${ }^{24}$

\section{Induction of diabetes mellitus}

Diabetes mellitus was induced in all the animal groups except normal control group 1, by a single intraperitoneal shot of STZ $(65 \mathrm{mg} / \mathrm{kg})$ dissolved in citrate buffer ( $\mathrm{pH} 4.5$ ). Fasting blood glucose (FBG) level measured just prior to STZ injection using an automated glucometer (Accue-check, Germany). Blood samples collected using capillary tube from the eye of the animal to the glucometer strip (oxidase strips) animals with glucose level greater than $200 \mathrm{mg} / \mathrm{dl}$ was used for the study after 3 days of diabetes mellitus induction. Blood glucose level estimation was repeated at the end of each week of during study.

\section{Wound creation}

A full thickness excision wound was made on the dorsal rat skin after hair shaving by electrical clipper and shaved area was sterilized with $70 \%$ alcohol. Excision wounds were made by removing a $4 \mathrm{~cm}^{2}$ piece of skin using toothed forceps and pointed scissors the day at which the wound is made will be considered day 0 .

PPE (400 mg/kg or $600 \mathrm{mg} / \mathrm{kg}$ ) and POE (300 mg/kg) both plants powdered extracts dissolved in distilled water administered using a gastric tube for each rat according to animal's weight within both treatment groups for 21 days. Rats in the control groups (Group 1 and 2) received $2 \mathrm{ml} / \mathrm{kg}$ of normal saline. Progressive changes in wound size were reported and photographed using digital camera at days (0, 7 and 21) during study respectively. The wound size measured using Vernier calliper every 7 days and the percentage of wound size reduction during the study was calculated using the following formula:

$$
\text { Wound reduction percentage }=\left(\mathrm{W}_{0}-\mathrm{W}_{\mathrm{t}} / \mathrm{W}_{0}\right) * 100 \%
$$

Where $\mathrm{W}_{0}$ is wound diameter on day zero,

$\mathrm{W}_{\mathrm{t}}$ is wound diameter on day $\mathrm{t}$.

The percentage of wound closure on days 7, 14 and 21 recorded and used as indicator of wound healing changes during the study.

Calculation of the time taken for $50 \%$ of wound closure $\left(\mathrm{WC}_{50}\right)$ was calculated by plot of percentage of wound closure against time during study periods.

\section{Biochemical analysis}

At the end of the study, day 21, animals from each group sacrificed and the entire wound cut out and stored at $-70^{\circ} \mathrm{C}$ for further analysis of total protein and hydroxyproline deposited as wound healing parameters.

\section{Estimation of total protein content of healed wound}

Skin tissue lysate was prepared by homogenization in modified Radio Immuno Precipitated Assay (RIPA) buffer. Estimation of total protein content of granulation tissue taken from healed excised wound was done by using commercially made animal kit. Procedure used based on Peterson's modification of the micro Lowry method (Peterson G.I. 1977), the procedure is based on two chemical reactions. The first is the biuret reaction, in which the alkaline cupric tartrate reagent complexes with the peptide bonds of the protein. This is followed by the reduction of the Folin and Ciocalteu's phenol reagent, which yields a purple color. 
Abudayeh, et al:: Pomelo Extract Effect in Wound Healing

Absorbance of the colored solution is read at a suitable wavelength at $600 \mathrm{~nm}$. The protein concentration is determined from a calibration curve prepared from different dilutions of Stock aqueous BSA solutions. ${ }^{25}$

\section{Estimation of Hydroxyproline content}

According to (Peng-Tung and Cheng H.) ${ }^{26}$ a $50 \mathrm{mg}$ of dried granulation tissue will be hydrolysed in $4 \mathrm{M} \mathrm{HCl}$ in a test tube for $22 \mathrm{~h}$ at $110^{\circ} \mathrm{C}$ then the content of the test tube will be transferred into $25 \mathrm{ml}$ volumetric flask diluted with distilled water, then $1 \mathrm{ml}$ of this solution is transferred into $50 \mathrm{ml}$ tube to which 1-propanol and the oxidant solution will be added to the tube, then the content of the tube will be mixed for $4 \mathrm{~min}$. After that Ehrlich reagent will be added to the mixture and the tube cap will be screwed tightly and the solution will be mixed again under fume hood. After that the tube will be heated in a water bath at $60^{\circ} \mathrm{C}$ for $25 \mathrm{~min}$ and then we will cool the tube using tab water for 2-3 min and read the absorbance at $558 \mathrm{~nm}$ within 2-3h. Hydroxyproline concentrations will be calculated from the linear standard curve. ${ }^{26}$

\section{Statistical analysis}

All the results were expressed as mean \pm SEM.Students " $t$ " test was used for determining the significance between mean of treatment with different doses of PPE and standard plant POE for wound healing compared with both control groups. One-way analysis of variance (ANOVA) and Tukey test was used for the statistical analysis of means difference among study periods within each group. A probability value of $p<0.05$ was considered significant.

\section{RESULTS}

The effect of pomelo peel extract treatment onthe percentage wound size reduction.

Results in Table 1 demonstrate the statistical difference among different study groups during the wound healing periods showed that wound size contraction percentage of both PPE $400 \mathrm{mg} \backslash \mathrm{kg}$ and $600 \mathrm{mg} / \mathrm{kg}$, respectively was significantly different during study days as compared with both control groups and $\mathrm{POE}$ as approved standard plant for wound healing treatment group $(\mathrm{P}<0.05)$. On the other hand, the percentage of the wound contraction was higher on the $21^{\text {th }}$ day as compared with normal control groups, but the difference was not significant. In addition, Figure 1. showed photographic representation for excision wound made showed contraction progress during different study periods among study groups. As shown in Table 1 the time took for wound to reach $\mathrm{WC}_{50}$ during both PPE $400 \mathrm{mg} / \mathrm{kg}$ and $600 \mathrm{mg} / \mathrm{kg}$ treatment groups showed shorter time of (11.7) and (9.2) days respectively, Compared to diabetic control group (15.3) days comparable to that took for wound healing during standard plant treatment period.

The effect of pomelo peel extract and standard plant treatment on total protein and hydroxyproline in excised wound model

Table 2 showed the effect of different doses of PPE and standard plant POE treatment on hydroxyproline and total protein levels in excised wound models. Results of collected excised granulation tissue from healed wound at the end of the study (day 21), the hydroxyproline content in the granulation tissue collected from rats treated with both

Table 1: The effect of pomelo peel extract and standard plant treatment on the percentage wound size reduction among normal and hyperglycemic rats during the period of wound healing.

\begin{tabular}{|c|c|c|c|c|c|}
\hline \multirow{2}{*}{ Groups } & \multirow{2}{*}{$\mathrm{N}$} & \multicolumn{3}{|c|}{ Percentage of Wound size reduction along study } & \multirow{2}{*}{$\mathrm{WC}_{50}$} \\
\hline & & Day 7 & Day 14 & Day 21 & \\
\hline Normal control & 8 & $34.07 \pm 2.78$ & $78.11 \pm 2.61^{*}$ & $91.15 \pm 1.28^{*}$ & 10.9 \\
\hline Diabetic control & 8 & $22.03 \pm 1.58$ & $57.00 \pm 0.8^{*}$ & $79.12 \pm 1.38^{*}$ & 15.3 \\
\hline Pomelo Peel Extract (PPE) $400 \mathrm{mg} / \mathrm{kg}$ & 8 & $34.81 \pm 1.46^{\mathrm{bd}}$ & $71.64 \pm 1.97^{\mathrm{bd} x}$ & $90.16 \pm 0.99^{\mathrm{b} *}$ & 11.7 \\
\hline Pomelo Peel Extract (PPE) $600 \mathrm{mg} / \mathrm{kg}$ & 8 & $42.96 \pm 1.46^{\mathrm{abc}}$ & $84.10 \pm 1.55^{\mathrm{abc} *}$ & $93.77 \pm 0.73^{\text {bc* }}$ & 9.2 \\
\hline Portulaca Oleracea Extract (POE) $300 \mathrm{mg} / \mathrm{kg}$ & 8 & $41.78 \pm 1.92^{\mathrm{ab}}$ & $81.20 \pm 1.14^{\text {b* }}$ & $91.82 \pm 1.10^{\mathrm{b} *}$ & 9.3 \\
\hline
\end{tabular}

Data expressed as mean \pm SEM, n: number of animals within the group

a: Significant difference between treatment with different doses of PPE or POE as compared with normal control group using student $t$-test $(p<0.05)$

$\mathrm{b}$ : Significant difference between treatment with different doses of PPE or standard POE treatment as compared with diabetic control group using student t-test $(p<0.05$ ) c: Significant difference between treatment with PPE $400 \mathrm{mg} / \mathrm{kg}$ group compared with $600 \mathrm{mg} / \mathrm{kg}$ group using student t-test $(p<0.05)$

d: Significant difference between treatment with different doses of PPE as compared with standard plant POE treatment group using student t-test $(p<0.05)$

${ }^{*}$ Significant difference between means among different study periods within each group using ANOVA and Tukey test $(P<0.05)$. Wc ${ }_{50}$ : each value represents the time taken for $50 \%$ wound closure.

Table 2: the effect of pomelo peel extract and standard plant treatment on total protein and hydroxyproline in granulation tissue of healed excised wound among normal and hyperglycemic rats at the end of the study.

\begin{tabular}{cccc}
\hline Groups & N & Hydroxyproline $(\mathrm{mg} / \mathrm{g})$ & Total protein $(\mathrm{mg} / \mathrm{g})$ \\
\hline Normal Control & 8 & $17.97 \pm 0.27$ & $237.01 \pm 3.03$ \\
Diabetic control & 8 & $13.16 \pm 0.49$ & $181.97 \pm 4.47$ \\
Pomelo Peel Extract(PPE) $400 \mathrm{mg} / \mathrm{kg}$ & 8 & $19.61 \pm 0.44^{\mathrm{abd}}$ & $259.43 \pm 4.95^{\mathrm{abd}}$ \\
Pomelo Peel Extract(PPE) $600 \mathrm{mg} / \mathrm{kg}$ & 8 & $23.09 \pm 0.77^{\mathrm{abc}}$ & $375.61 \pm 11.52^{\mathrm{abc}}$ \\
Portulaca Oleracea Extract (POE) $300 \mathrm{mg} / \mathrm{kg}$ & 8 & $21.58 \pm 0.58^{\mathrm{ab}}$ & $347.38 \pm 13.84^{\mathrm{ab}}$ \\
\hline
\end{tabular}

Data expressed as mean \pm SEM., n: number of animals within the group.

a: Significant difference between treatment with different doses of PPE or POE as compared with normal control group using student $t$-test ( $p<0.05$ )

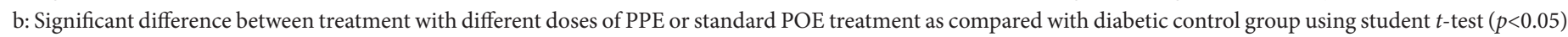

c: Significant difference between treatment with $400 \mathrm{mg} / \mathrm{kg}$ treatment group compared with that of (PPE $600 \mathrm{mg} / \mathrm{kg}) \mathrm{group}$ using student $t$-test $(p<0.05)$

$\mathrm{d}$ : Significant difference between treatment with different doses of PPE as compared with standard plant POE treatment group using student $t$-test ( $p<0.05$ ). 
Table 3: The effects of pomelo peel extract and standard plant treatment on fasting blood glucose level of normal and hyperglycemic rat during the period of wound healing.

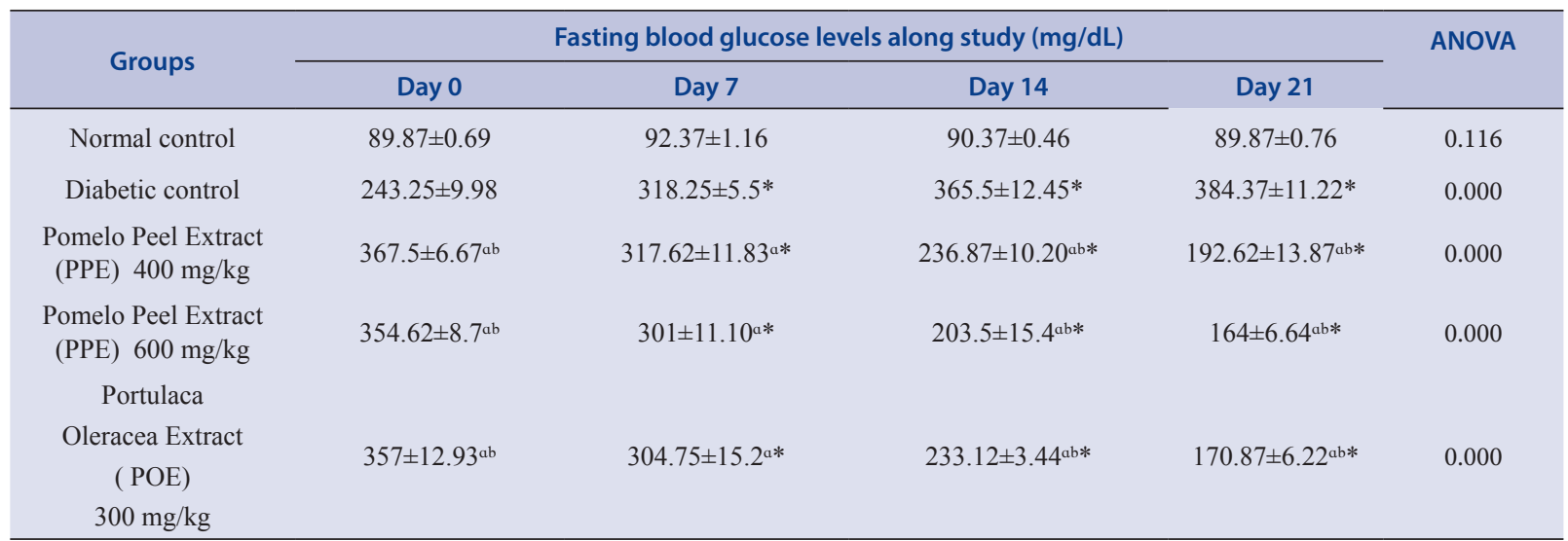

Data expressed as mean \pm SEM., n: number of animals within the group

a: Significant difference between treatment with different doses of PPE or POE as compared with normal control group using student $t$-test $(p<0.05)$

b: Significant difference between treatment with different doses of PPE or standard POE treatment as compared with diabetic control group using student $t$-test ( $p<0.05$ )

c: Significant difference between treatment with PPE $400 \mathrm{mg} / \mathrm{kg}$ group compared with $600 \mathrm{mg} / \mathrm{kg}$ group using student $t$-test $(p<0.05)$

d: Significant difference between treatment with different doses of PPE as compared with standard plant POE treatment group using student $t$-test $(p<0.05)$

* Significant difference between means among different study periods within each group using ANOVA and Tukey test $(P<0.05)$

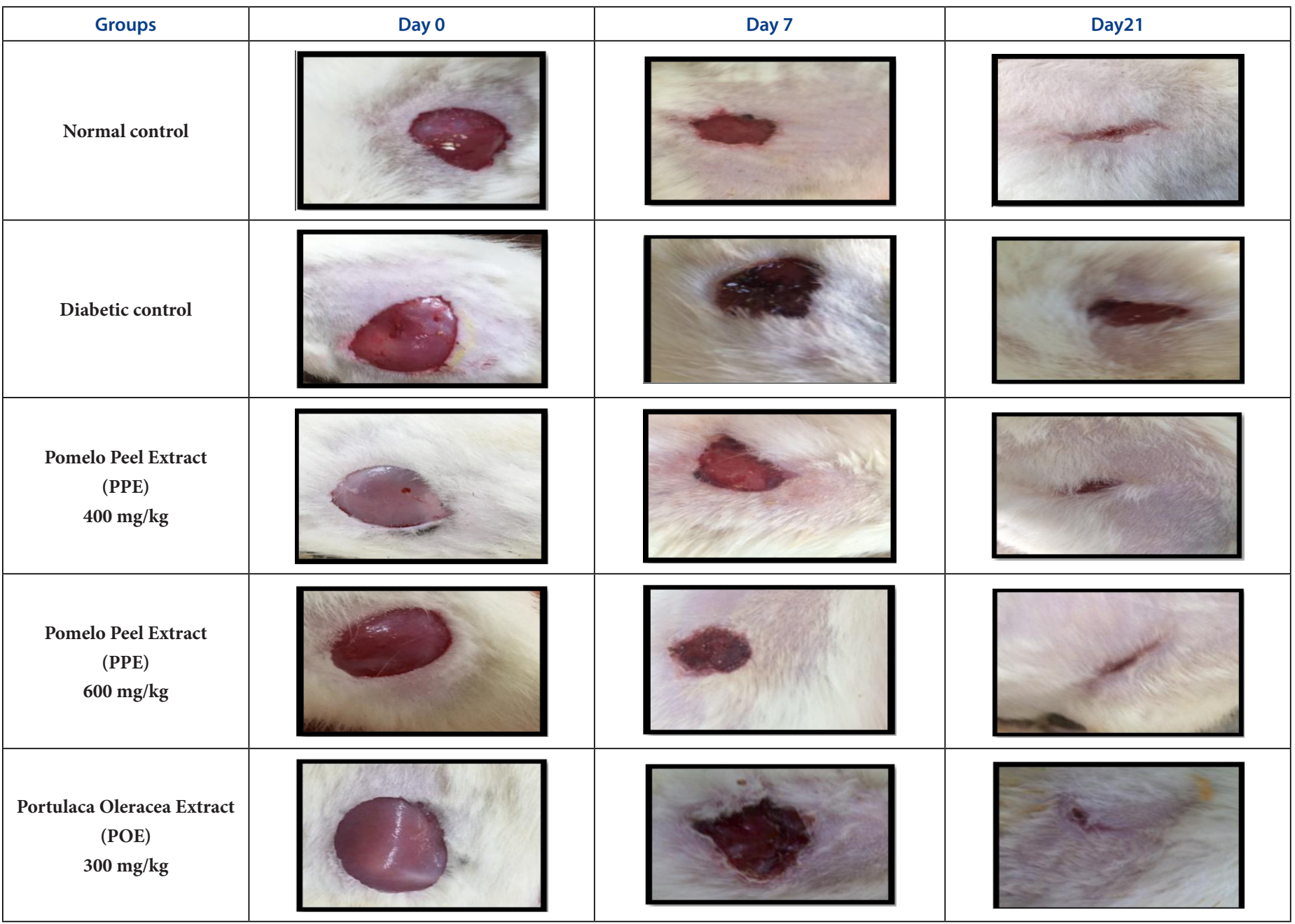

Figure 1: Photographic representation of wound contraction progress during different study periods among study group. 
doses of the extract $400 \mathrm{mg} \backslash \mathrm{kg}$ and $600 \mathrm{mg} / \mathrm{kg}$ PPE groups was significantly different from that observed in both normal and diabetic control groups, $(P<0.05)$. As compared to the hydroxyproline content in the granulation tissue collected from rats treated with POE standard plant showed comparable results.

The effect of pomelo peel extract treatment on the fasting blood glucose level

As shown in Table 3, for the effects of different doses of pomelo peel extract and POE as standard plant showed different effect on fasting blood glucose level of normal and hyperglycemic rats before and during the period of the wound healing, Rats included within both PPE $(400 \mathrm{mg} \backslash \mathrm{kg}$ and $600 \mathrm{mg} / \mathrm{kg}$ ) groups fasting blood glucose was significantly different as compared to both normal and diabetic groups $(\mathrm{P}<0.05)$, then decrease during treatment with PPE along study period which was lower than the blood glucose level of the diabetic control group with comparable results to those rats treated with POE standard plant group and this reduction started from $7^{\text {th }}$ day of the study among the three treatment groups (both PPE and POE treated groups reaching significant level and continue reduction till day 21 end of the study $(p<0.05)$.

\section{DISCUSSION}

Impaired wound healing is a common complication of diabetes mellitus which is well-known factor that can affect the process of wound healing in which wound healing is achieved in diabetic subjects by decreasing the blood glucose level and increase hydroxyproline and total protein production, the increase in wound size contraction percentage is considered a good sign of a successful wound healing. ${ }^{27-28}$ Wound healing is a natural process of regenerating dermal and epidermal tissue, previous literatures shown the beneficial role of vitamin $\mathrm{C}, \mathrm{A}$ and flavonoids to enhance and accelerate healing process. ${ }^{29-30}$ The role of vitamin $\mathrm{C}$ as a powerful anti-oxidant and it's the presence with flavonoids and carotenoids increased their wound healing efficacy mentioned in many previous studies. ${ }^{27,31}$ Wound repair in diabetic rats is associated with reduced collagen (hydroxyproline) and other protein synthesis in granular tissue. ${ }^{29}$ Vitamin A and $\mathrm{C}$ deficiencies result in impaired wound healing have been linked to decreased collagen synthesis ,decreased angiogenesis and increased susceptibility to wound infection. ${ }^{32-33}$ The result of this study showed great beneficial effect of pomelo peel extract in two different doses PPE (400 mg/kg and $600 \mathrm{mg} / \mathrm{kg}$ ) on rate of healing of externally made excision wound in diabetic rats, the effect of the extract on the percent of wound contraction was significant $(\mathrm{p}<0.05)$ (Table 1$)$ compared to both control groups while showed comparable effect to that obtained by rats treated with POE standard plant for wound healing confirmed by photographic representation of excised wound changes during different study periods (Figure 1). Moreover, Table 2 showed that high amount of hydroxyproline and total protein extracted from granulation tissue of healed excised wound at the end of the study indicate a better wound contraction due to the increase of collagen formation and increase the amount of protein by pomelo peel extract PPE treated groups which was significantly different from that of both diabetic control and normal control groups, these results were comparable to other previous studies for wound healing. ${ }^{27,31-32}$ (Erdinc K. et al. 2010 , Szyszkowska B et al. 2014) in their study pomelo content of flavonoids, carotenoids and vitamin C, enhances the epithelial cells migration, proliferation and stimulate collagen synthesis. ${ }^{34-35}$ The increase in the hydroxyproline and total protein content are indicators of new tissues generation.

In this study, the effect of PPE on the FBG which was reduced, compared to that of diabetic control group showing elevated FBG before enrolment in the study by intraperitoneal STZ injection induces glucose over production through excessive hepatic glycogenolysis or gluconeogenesis and decreased utilization of glucose by the tissues are the fundamental basis of hyperglycemia in diabetes mellitus. ${ }^{36}$ During PPE treatment there was significant reduction of FBG level progress till the end of the study compared to both control groups $(p<0.05)$ whereas comparable to that obtained by treatment with standard plant (Table 3 ).

The two major flavonoids of citrus maxima are naringenin and hesperidin are proven to be hypoglycemic agents and their hypoglycemic activity is mediated by their ability to inhibit intestinal $\alpha$-glycosidase activity which is a key enzyme of carbohydrate digestion located on intestinal cells, thereby delaying the absorption of carbohydrates in diabetic animals (Jung UJ et al. 2004, KnuduSen S et al. 2011) suggested that hesperidin may have the ability to protect pancreatic Beta cell from STZ actions and restore their ability to secret insulin. ${ }^{37,38}$ Published data show wide phytochemical composition and pharmacological action of citrus maxima fruits. Our study proved wound healing effect of pomelo peel. We can assume that the main compounds which are responsible for wound healing action are flavonoids and vitamins. The aim of future work will be phytochemical study of PPE.

\section{CONCLUSION}

This study demonstrated that PPE had significant wound healing demonstrated by significant wound size reduction, high content of granulation hydroxyproilne and total protein content taken from healed wound with improvement of blood glucose levels of the treated groups compared to the standard, finally this study proposed that oral administration of PPE has a good therapeutic potential in the treatment of complicated wounds in diabetes.

\section{ACKNOWLEDGEMENT}

The authors are grateful to ISRA UNIVERSITY administration for providing facilities and funds for this work.

\section{CONFLICT OF INTEREST}

We declare no conflict of interest.

\section{ABBREVIATIONS}

STZ: Streptozotocin; PPE: Pomelo Peel Extract; POE: Portulaca Oleracae Extract; $\mathbf{W C}_{50}$ : the time taken for $50 \%$ of wound closure; RIPA : Radio Immuno Precipitated Assay; BSA: Bovine Serum Albumin; ANOVA: Analysis of variance; FBG: Fasting Blood Glucose.

\section{REFERENCES}

1. Dhall S, Do DC, Garcia M, Kim J, Mirebrahim SH, Lyubovitsky J, et al. Generating and reversing chronic wounds in diabetic mice by manipulating wound redox parameters. J Diabetes Res. 2014;2014. Article ID 562625, 18 p.doi:10.1155/2014/562625.

2. Tatiana N, Demidova R, Michael RH, Ira MH. Acute and Impaired Wound Healing: Pathophysiology and Current Methods for Drug Delivery, Part 1: Normal and Chronic Wounds: Biology, Causes, and Approaches to Care. Adv Skin Wound Care. Adv Skin Wound Care. 2012;25(7):304-14. doi:10.1097/01. ASW.0000416006.55218.d0.

3. Rodrigo RG, Rosique MJ, Junior F, Jayme AF. Curbing Inflammation in Skin Wound Healing: international Journal of Inflammation. 2015. Article ID 316235, 9 p. http://dx.doi.org/10.1155/2015/316235

4. Guo SA, Dipietro LA. Factors affecting wound healing. J Dent Res. 2010;89(3):219-29. doi:10.1177/0022034509359125

5. Hirsch T, Spielmann M, Zuhaili B, Koehler T, Fossumet M, Steinau HU, et al. Enhanced susceptibility to infections in diabetic wound healing model. BioMed Central (BMC) Surg. 2008;8(1):5. doi:10.1186/1471-2482-8-5.

6. Rúben FP, Paulo JB. Traditional Therapies for Skin Wound Healing. Adv Wound Care (New Rochelle). 2016;5(5):208-29. doi:10.1089/wound.2013.0506.

7. Uzun A, YesilogluT. Genetic Diversity in Citrus. In Mahmut Caliskan(Ed), Genetic Diversity in Plants, Prof. (Ed.), ISBN: 978-953-51-0185-7, In Tech. 2012:213-31. Available from: http://www.intechopen.com/books/geneticdiversity-inplants/ 
genetic-diversity-in-citrus.

8. Lai CS, Li S, Miyauchi Y, Suzawa M, Ho CT, Pan MH. Potent anti-cancer effects of citrus peel flavonoids in human prostate xenograft tumors. Food Funct. 2013;4(6):944-9. doi: 10.1039/c3fo60037h

9. Caengprasath N, Ngamukote S, Mäkynen K, Adisakwattana S. The protective effects of pomelo peel extract (citrus grandis L. osbeck) against fructose-mediated protein oxidation and glycation. Food Funct. 2013;4(6):944-9. doi:10.1039/ c3fo60037h

10. Kanes KB, Tisserat MA, Vandercook BC. Phenolic composition of various tissues of Rutaceae species. Phytochemistry. 1993;32(4):967-74

11. Assini JM, Mulvihill EE, Sutherland BG, Telford DE, Sawyez CG, Felder SL, et al. Naringenin prevents cholesterol-induced systemic inflammation, metabolic dysregulation, and atherosclerosis in mice. J Lipid Res. 2013;54(3):711-24. doi:10.1194/jIr.M032631.

12. Lai C, Li S, Miyauchi Y, Suzawa M, Ho C, Pan M. Potent anti-cancer effects of citrus peel flavonoids in human prostate xenograft tumors. Food and Function. 2013;4(6):944-9. doi:10.1039/c3fo60037h.

13. Kannappan S, Anuradha CV. Naringenin enhances insulin-stimulated tyrosine phosphorylation and improves the cellular actions of insulin in a dietary model of metabolic syndrome. Eur J Nutr. 2010;49(2):101-9. doi:10.1007/s00394-009 0054-6.

14. Ronchetti IP, Quaglino D, Bergamini G. Ascorbic acid and connective tissue Subcell Biochem. 1996;25:249-64.

15. Opara EC. Role of oxidative stress in the etiology of type 2 diabetes and the effect of antioxidant supplementation on glycemic control. J Investig Med. 2004;52(1):19-23. doi: 10.1136/jim-52-01-22.

16. Senel O, Cetinkale O, Ozbay G, Ahçioglu F, Bulan R. Oxygen free radicals impair wound healing in ischemic rat skin. Ann Plast Surg. 1997;39(5):516-23.

17. Wang L, Wang J, Fang L, Zheng Z, Zhi D, Wang S, et al. Anticancer activities of Citrus peel polymethoxy flavones related to angiogenesis and others. BioMed Research International. Vol. 2014. Article ID 453972,10 p. http://dx.doi. org/10.1155/2014/453972

18. Chowdhury MR, Sagor AT, Tabassum N, Potol A, Hossain H, Alam A. Supplementation of Citrus maxima peel powder prevented oxidative stress, fibrosis, and hepatic damage in carbon tetrachloride $(\mathrm{CCl} 4)$ treated rats. Evidence-Based Complementary and Alternative Medicine Vol. 2015. Article ID 598179, 10 p. http://dx.doi.org/10.1155/2015/598179.

19. Oyedepo TA. Effect of Citrus maxima (Merr.) Fruit Juice in Alloxan-Induced Diabetic Wistar Rats. Science Journal of Medicine and Clinical Trial. 2012. Article ID sjmct-125, 8 p. doi: 10.7237/sjmct/125

20. Dubey Nk, Kumar R, Tripathi P. Global promotion of herbal medicines: India's Opportunity. Curr Med. 2004;86(1):37-41.

21. Singh A, Navneet. Citrus maxima (Burm) Merr. A traditional medicine: Its antimicrobial potential and pharmacological update for commercial exploitation in herbal drugs. International Journal of ChemTech Research. 2017;10(5):642-51.

22. Abeysinghe DC, Xian Li, Sun C, Zhang WS, Zhou CH, Chen SK. Bioactive compounds and antioxidant capacities in different edible tissues of citrus fruit of four species. Food Chem. 2007;104(4):1338-44

23. Trease GE, Evans MC. Textbook of Pharmacognosy, 12th. Edition, Balliere, Tindal London. 1983:57-9.

24. Rashed AN, Afifi FU, Disi AM. Simple evaluation of the wound healing activity of a crude extract of Portulaca oleracea L. (growing in Jordan) in Mus musculus JVI-1. Journal of Ethno Pharmacology. 2003;88(2-3):131-6

25. Peterson GL. A simplification of the protein assay method of Lowry et al. Which is more generally applicable. Analytical Biochemistry. 1977;83(2):346-56. doi. org/10.1016/0003-2697(77)90043-4

26. Tung $P$, Cheng $H$. An improved method for the determination of hydroxyproline in rat skin. The Journal of Investigative Dermatology. 1969;53(2):112-5. doi. org/10.1038/jid.1969.116.

27. Ahmad M, Ansari MN, Alam A, Khan TH. Oral Dose of Citrus Peel Extracts Promotes Wound Repair in Diabetic Rats. Pakistan Journal of Biological Sciences. 2013;16(20):1086-94. doi:10.3923/pjbs.2013.1086.1094

28. Singer AJ, Clark RA. Cutaneous wound healing. 1999;341(10):738-46. doi:10.1056/NEJM199909023411006.

29. Sarpooshi HR, Haddadi M, Siavoshi M, Borghabani R. Wound Healing with Vitamin C. Transl Biomed. 2017;8(4):139-42.

30. Stipcevic T, Piljac J, Vanden BD. Effect of different flavonoids on collagen synthesis in human fibroblasts. Plant Foods Hum Nutr. 2006;61(1):27-32. doi:10.1007/ s11130-006-0006-8.

31. Lodhi S, Singhai AK. Wound healing effect of flavonoid rich fraction and lutein isolated from Martynia annua Linn. On streptozotocin induced diabetic rats. Asian Pac J Trop Med. 2013;6(4):253-9. doi: 10.1016/S1995-7645(13)60053-X.

32. Arnold M, Barbul A. Nutrition and wound healing. Plast Reconstr Surg. 2006;117(7S):42S-58S. doi:10.1097/01.prs.0000225432.17501.6c.

33. Campos AC, Groth AK, Branco AB. Assessment and nutritional aspects of wound healing. Curr Opin Clin Nutr Metab Care. 2008;11(3):281-8. doi: 10.1097/ MCO.ob013e3282fbd35a

34. Erdinc K, Haluk RU, Omer G, Gulden D, Ragip O, Murat O, et al. Effect of Ascorbic Acid on Incisional Wound Healing in Streptozotocin-Induced Diabetic Rats. Wounds. 2010;22(2):27-31.

35. Szyszkowska B, Łepecka-Klusek C, Kozłowicz K, Jazienicka I, Krasowska D. The influence of selected ingredients of dietary supplements on skin condition. Dermatol Alergol. 2014;31(3):174-81. doi: 10.5114/pdia.2014.40919.

36. Elsner M, Guldbakke B, Tiedge M, Munday R, Lenzen S. Relative importance of transport and alkylation for pancreatic beta-cell toxicity of streptozotocin. Diabetologia. 2000;43(12):1528-33. doi:10.1007/s001250051564.

37. Jung UJ, Lee MK, Jeong K, Choi MS. The hypoglycemic effects of hesperidin and naringin are partly mediated by hepatic glucose-regulating enzymes in C57BL/KsJ-db/db mice. J Nutr. 2004;134(10):2499-503.

38. KnuduSen S, Gupta M, Mazumder UK, Haldar PK, Saha P, Bhattacharya S, et al. Antihyperglycemic effect and antioxidant property of Citrus maxima in streptozotocin induced diabetic rats. Diabetologia Croatica. 2011;40(4):113-20.

\section{GRAPHICAL ABSTRACT}

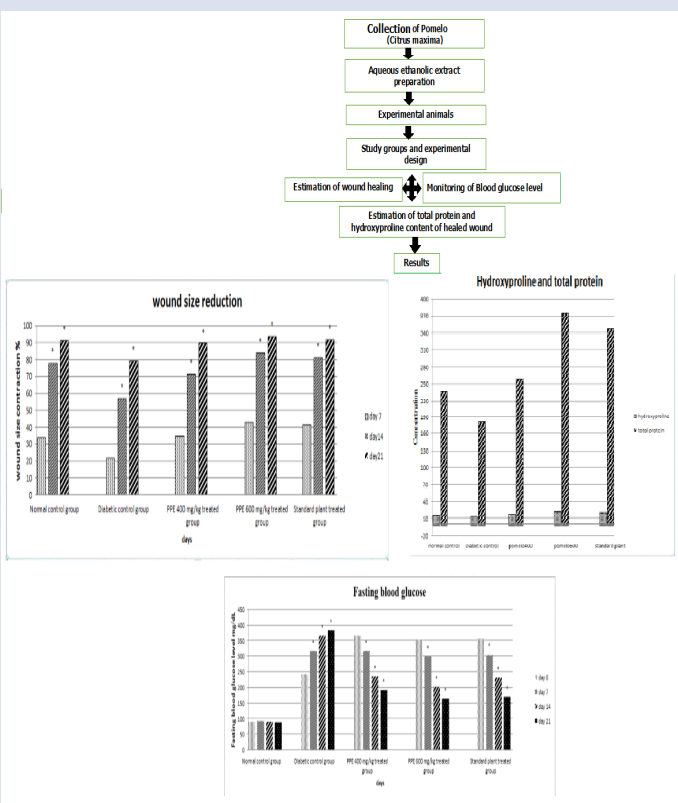

\section{SUMMARY}

- In this work the review has been made on the articles of various studies on the plant Citrus maxima.

- Extraction and preparation of Pomelo (Citrus maxima) peels extract

- Evaluation of the effect of different doses of pomelo (Citrus maxima) peel extract on experimentally made skin excision wound healing in diabetic compared to untreated control groups using diabetes induced animal models during 3 weeks study and estimation of granulation protein from healed wound area at the end of study.

\section{ABOUT AUTHORS}

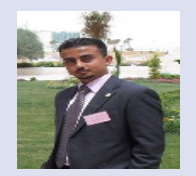

Asser Ashraf Ahmad: Master Degree Holder from the Al-Isra University/Applied Pharmaceutical Science and Clinical Pharmacy Departmen /Faculty of Pharmacy, Amman- JORDAN. Currently working in the Al-Isra University as an assistant researcher in pharmaceutical sciences. 
Ihab Ibrahim Al Khalifa: He worked at Applied Pharmaceutical Science and Clinical Pharmacy Department/ Faculty of Pharmacy, Al-Isra University, Amman- JORDAN. Currently works at the Alrasheed university/pharmacy department -Iraq. His last published work is 'Cigarette Smoking as a Relative Risk Factor for Metabolic Syndrome- J Endocrinol Metab.

Zead Helmi Abudayeh: He works at an university of Al-Isra/ Applied Pharmaceutical Science and Clinical Pharmacy Department / Faculty of Pharmacy, Amman- JORDAN. His research interests focus on isolation and purification of active ingredients from medicinal plants and the study their potential therapeutic effect on animals. Also partially working with synthesis of novel compounds for treating Alzheimer disease.

Cite this article: Ahmad AA, Khalifa IIA, Abudayeh ZH. The Role of Pomelo Peel Extract for Experimentally Induced Wound in Diabetic Rats. Pharmacog J. 2018;10(5):885-91. 